\title{
OPTIMIZATION OF UHPFRC BEAMS SUBJECTED TO BENDING USING GENETIC ALGORITHMS
}

\author{
Goran ĆIROVIĆ, Vlastimir RADONJANIN, Milan TRIVUNIĆ, Dragan NIKOLIĆ \\ Institute for Testing Materials, Faculty of Technical Science, Concrete Labaratory, University of Novi Sad, \\ Bul. vojvode Misica 43, Belgrade, Serbia
}

Received 31 Jan 2012; accepted 12 Apr 2012

\begin{abstract}
Ultra high performance fibre reinforced concrete (UHPFRC) is cementitious composite with very high strength, and when compared with ordinary concrete it is a more superior material both in terms of its mechanical properties and its durability. In order to predict the behaviour of UHPFRC beams, first of all, experiments were carried out to investigate the mechanical properties of composites containing $2 \%$ and $4 \%$ of steel fibres. Following this, four beams of $2 \mathrm{~m}$ in length were tested by subjecting to four point bending. Two beams contained only micro steel fibres, while the remaining two contained conventional steel bar reinforcement. On the basis of experimental studies and recommendations by the AFGC for UHPC, the behaviour of the beams was modelled and optimization was carried out using genetic algorithms (GA) according to the criterion of minimum price. In this paper, the prices of individual UHPFRC beams are also shown in comparison with beams, which contain steel bars or prestressed reinforcement.
\end{abstract}

Keywords: ultra high performance fibre reinforced concrete, optimization, beams, genetic algorithms.

Reference to this paper should be made as follows: Ćirović, G.; Radonjanin, V.; Trivunić, M.; Nikolić, D. 2014. Optimization of UHPFRC beams subjected to bending using genetic algorithms, Journal of Civil Engineering and Management 20(4): 527-536. http://dx.doi.org/10.3846/13923730.2013.801908

\section{Introduction}

Ultra high performance concrete (UHPC), which has very high mechanical properties (compressive strength $>150 \mathrm{MPa}$ and tensile strength $>10 \mathrm{MPa}$ ), is a relativity new cement-based composite material (Habel et al. 2006; Kang et al. 2010). There are dozens of applications for this type of concrete but its implementation is still exceptional because improving the properties of materials is almost always followed by a high increase in the unit price of such materials, often rendering them economically unacceptable. Optimization of cross-section dimensions of construction elements (Marti, Vidosa 2010) and used high performance cement composites in composite beams (Lapko et al. 2005) may lead to economically justified applications of UHPFRC.

Improvement of the material properties is achieved by improving the microstructure of the materials using modern technical and technological developments (Yazic1 2007; Cwirzen et al. 2008). Modern technology and innovation in the production of concrete elements continue the trend of producing superior materials and structural elements from these materials (Ding et al. 2011).

The validity of using UHPC should be seen in terms of the full utilization of its achieved mechanical properties, optimization of the proportion of steel fibres, silica fume, cement, and also when UHPC is combined with conventional, prestressed or FRP reinforcement (Yang et al. 2010; Campione 2008; Ranković et al. 2010). Extremely high mechanical properties and improved durability of UHPC are achieved by applying the latest generation of superplasticizers, which make the high degree of water reduction in the concrete mixture. In comparison with conventional concrete, UHPC is a much more homogenous material with reduced porosity and improved microstructure (Rougeau, Borys 2004).

The use of quartz sand or aggregates of volcanic origin, the elimination of large fractions of aggregates, the application of extremely low water/binder ratios, reducing the $\mathrm{CaO} / \mathrm{SiO}$ factors by adding silica fume (or other mineral additives with high silica content), the addition of steel fibres and the use of hydrothermal processing in order to improve the microstructure all represent a generalised approach to designing a mixture of UHPC (Yang et al. 2009).

One of the extremely negative properties of concrete with high mechanical properties is that when increasing the compressive strength, it shows very brittle behaviour (Dvorkin et al. 2011; Arslan, Chinali 2010). An effective way of overcoming this problem is by adding steel fibres to the concrete mix.

Composing a UHPC mixture is not a simple and straightforward process. The properties of fresh and hardened concrete are affected by small variations in the cement composition and by chemical additives (Malešev et al. 2002) as well as their mutual compatibility. The 
distribution of the particle size of the fillers has an extremely significant impact on the properties of UHPC, and a problem may also arise in the use of locally available materials, which are not of constant quality and whose properties are not regularly tested.

UHPFRC is considered a very ductile material. According to the provisional recommendations for calculating these types of composites, the strain limit after the appearance of cracks is calculated by measuring the width of the fracture and the length of the fibres, but it can have a value of up to $25 \%$. For analysis and calculation of the construction of UHPFRC, it is necessary for the mechanical properties of the material to be completely mathematically modelled, precise and relatively easy to apply. Compared to conventional concrete, whose most important parameter for definition is the constitutive equation for compressive strength, for UHPFRC tensile strength is an equally important parameter. It should be noted that with UHPFRC, tensile strength is a relatively independent parameter in relation to compressive strength.

Recent researches on Ultra High Performance Concrete presented detailed experimental studies on the flexural characteristics of ultra high performance concrete beams reinforced with steel fibres (Kang et al. 2010; Yang et al. 2010). With high tensile strength and large ductility continues to develop even after cracking as favourable behaviour under seismic loads and with the application of optimization techniques, this type of composite could become a much more frequently used material in the construction industry.

It is precisely genetic algorithms (GA) as a technique of evolutionary programming, which mimics natural evolutionary processes that is used for finding optimal solutions to a problem when the domain for the search is very broad with a large number of parameters. Camp et al. (2003) developed a procedure for the optimization of reinforced concrete frames using GA as recommended by the ACI. Govindaraj and Ramasamy (2005) developed an algorithm for the detailed calculation and optimization of continuous reinforced concrete beams. In their paper, Sobolev and Amirjanov (2010) presented an algorithm based on genetic algorithms, which makes it possible to model the packing density of the aggregate in concrete.

In this paper, the goal of the optimization of UHPFRC beams subjected to bending is referred to examining the economic feasibility of this type of cement composite. But, there are some problems in the use of UHPFRC. UHPFRC is affected by high self-desiccation and autogenous shrinkage due to its low water-to-binder ratio $(\mathrm{w} / \mathrm{b})$. Exposure to drying conditions and moisture loss during early ages are of particular concern in thin applications of UHPC (Ichinomiya et al. 2005; Cheung, Leung 2011; Zhutovsky, Kovler 2012).

\section{The mechanical properties of UHPFRC beams}

\subsection{The behaviour of UHPFRC when compressive stress is applied}

Models of concrete behaviour when compressive stress is applied describe one of the most important properties of concrete and are based on the observation of testing samples under controlled strain. When compared with metal, concrete is a very brittle material, and under certain loading conditions, demonstrates explosive behaviour when reaching the strain limit (Yang et al. 2010). At higher compressive strength, concrete shows a longer interval of linear behaviour. Under controlled strain, the linear dependence of stress and strain of UHPFRC is expressed almost to the point of peak stress. If the composite does not contain fibres it will not be a noticeable part of the socalled stress-strain softening relation (Redaelli, Muttoni 2007).
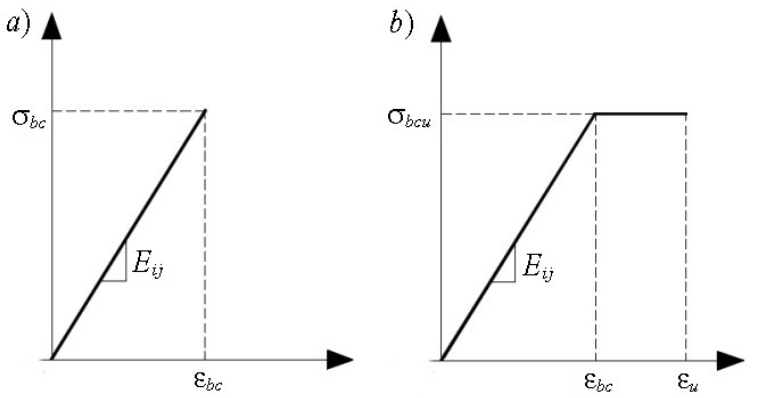

Fig. 1. Stress-strain diagram when compressive stress is applied (AFGC-SETRA 2002)

According to AFGC-SETRA recommendations, the linear dependence of stress and strain to peak strength are adopted without an increase in strain at constant pressure, that is, the softening part of the diagram for the serviceability limit state (Fig. 1-a). At the loading limit state there is a plateau in the strain increase up to $3.0 \%$ at constant stress $\sigma_{b c u}$ (Fig. 1-b).

For the serviceability limit state:

$$
\sigma_{b c}=0.6 \cdot f_{c j}
$$

where $f_{c j}$ is the characteristic compressive strength.

For the ultimate limit state:

$$
\sigma_{b c u}=0.85 \cdot \frac{f_{c j}}{\theta \gamma_{b}}
$$

where: $f_{c j}$ - the characteristic compressive strength; and $\gamma_{b}$ - the partial coefficient.

\subsection{The behaviour of UHPFRC when tensile stress is applied}

Modelling the loading capacity by applying tensile stress has a very important role in the optimization of beams. In the past decade, several advanced models within the framework of the mechanical fracture of quasi-brittle materials under applied tensile stress have been developed. Several approaches to modelling the dependence of UHPFRC stress and strain imply the existence of hardening with increased strain after linear dependence, followed by softening with increased strain in the stress-strain working diagram (AFGC-SETRA 2002; JSCE 2004). 
a)

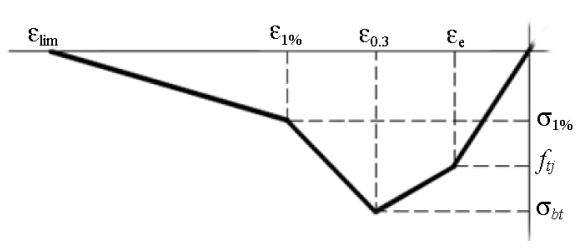

b)

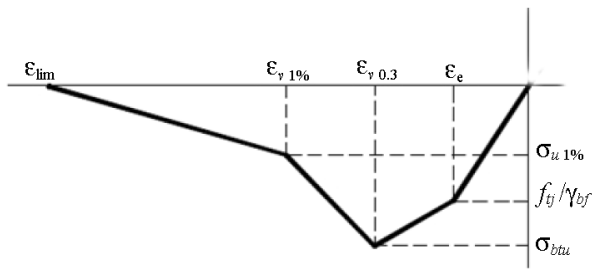

Fig. 2. Stress-strain when tensile stress is applied (AFGC-SETRA 2002)

For the serviceability limit state:

$$
\varepsilon_{e}=\frac{f_{t j}}{E_{e}}
$$

where: $f_{t j}$ is the elastic part of the tensile stress, which is obtained by testing prismatic samples by bending them (the elastic part of the dependence of load-deflection relationship); $E_{e}$ is the module of elasticity.

$$
\varepsilon_{0.3}=\frac{w_{0.3}}{l_{c}}+\frac{f_{t j}}{E_{e}},
$$

where: $w_{0.3}$ is the fracture width from $0.3 \mathrm{~mm}$; and $l_{c}$ is the characteristic fracture length (most commonly $2 / 3 \mathrm{~h}$, and $h$ is the beam height).

$$
\begin{aligned}
& F_{c}=\left\{\begin{array}{ll}
\frac{1}{2} \cdot b \cdot x \cdot \sigma_{b c u} \cdot \frac{\varepsilon}{\varepsilon_{b c}} & z a 0<\varepsilon \leq \varepsilon_{b c} \\
\frac{1}{2} \cdot b \cdot x \cdot \sigma_{b c u} \cdot \frac{\varepsilon_{b c}}{\varepsilon}+b \cdot x \cdot \sigma_{b c u} \cdot \frac{\varepsilon-\varepsilon_{b c}}{\varepsilon} & z a \varepsilon_{b c}<\varepsilon \leq-3.0 \%
\end{array} ;\right. \\
& \left(\frac{1}{2} \cdot \frac{f_{t j}}{\gamma_{b f}} \cdot b(h-x) \cdot \frac{\varepsilon_{t}}{\varepsilon_{e}} \quad z a \varepsilon_{t} \leq \varepsilon_{e}\right. \\
& \frac{1}{2} \cdot \frac{f_{t j}}{\gamma_{b f}} \cdot b(h-x) \cdot \frac{\varepsilon_{e}}{\varepsilon_{t}}+\frac{\frac{f_{t j}}{\gamma_{b f}}+\sigma_{b t u}}{2} \cdot b(h-x) \cdot \frac{\varepsilon_{t}-\varepsilon_{e}}{\varepsilon_{t}} \quad z a \varepsilon_{e} \leq \varepsilon_{t} \leq \varepsilon_{u, 0.3} \\
& F_{t}= \begin{cases}\frac{1}{2} \cdot \frac{f_{t j}}{\gamma_{b f}} \cdot b(h-x) \cdot \frac{\varepsilon_{e}}{\varepsilon_{t}}+\frac{\frac{f_{t j}}{\gamma_{b f}}+\sigma_{b t u}}{2} \cdot b(h-x) \cdot \frac{\varepsilon_{u 0.3}-\varepsilon_{e}}{\varepsilon_{t}}+ & z a \varepsilon_{u 0.3} \leq \varepsilon_{t} \leq \varepsilon_{u, 1 \%} \\
\frac{\sigma_{b t u}+\sigma_{u 1 \%}}{2} \cdot b(h-x) \cdot \frac{\varepsilon_{t}-\varepsilon_{u 0.3}}{\varepsilon_{t}} & ;\end{cases} \\
& \frac{1}{2} \cdot \frac{f_{t j}}{\gamma_{b f}} \cdot b(h-x) \cdot \frac{\varepsilon_{e}}{\varepsilon_{t}}+\frac{\frac{f_{t j}}{\gamma_{b f}}+\sigma_{b t u}}{2} \cdot b(h-x) \cdot \frac{\varepsilon_{u 0.3}-\varepsilon_{e}}{\varepsilon_{t}}+ \\
& \frac{\sigma_{b t u}+\sigma_{u 1 \%}}{2} \cdot b(h-x) \cdot \frac{\varepsilon_{u 1 \%}-\varepsilon_{u 0.3}}{\varepsilon_{t}}+\frac{\sigma_{u 1 \%}}{2} \cdot b(h-x) \cdot \frac{\varepsilon_{t}-\varepsilon_{u 1 \%}}{\varepsilon_{t}} \quad z a \varepsilon_{u 1 \%} \leq \varepsilon_{t} \leq \varepsilon_{l i m}
\end{aligned}
$$
bending).

$$
\varepsilon_{\text {lim }}=\frac{l_{f}}{4 l_{c}},
$$

where $l_{f}$ is the length of the steel fibres.

For the ultimate limit state:

where $w_{1 \%}$ is the fracture width equal to $0.01 \mathrm{H}(\mathrm{H}$ is the height of the prismatic sample tested when subject to

$$
\sigma_{b t}=\frac{\sigma\left(w_{0.3}\right)}{K} ; \quad \sigma_{1 \%}=\frac{\sigma\left(w_{1 \%}\right)}{K},
$$

where: $1 / \mathrm{K}$ is the coefficient which includes the difference in behaviour of the beam and the tested sample.

$$
\begin{gathered}
\varepsilon_{e}=\frac{f_{t j} / \gamma_{b f}}{E_{e}} ; \\
\varepsilon_{0.3}=\frac{w_{0.3}}{l_{c}}+\frac{f_{t j} / \gamma_{b f}}{E_{e}} ; \\
\varepsilon_{1 \%}=\frac{w_{1 \%}}{l_{c}}+\frac{f_{t j} / \gamma_{b f}}{E_{e}} ; \\
\sigma_{b t}=\frac{\sigma\left(w_{0.3}\right)}{K \gamma_{b f}} ; \sigma_{1 \%}=\frac{\sigma\left(w_{1 \%}\right)}{K \gamma_{b f}},
\end{gathered}
$$

where $\gamma_{b f}$ is the partial safety coefficient (1.3 for basic load combinations, 1.05 for incidental load combinations).

The total force in the pressed zone according to the specified model of behaviour is calculated as shown in (9). 


$$
F_{a}=\left\{\begin{array}{lc}
A_{s} \cdot \varepsilon_{s} \cdot E_{s} & z a \varepsilon_{s} \leq \frac{f_{y}}{E_{s}} \\
A_{s} \cdot \varepsilon_{y} & z a \frac{f_{y}}{E_{s}} \leq \varepsilon_{s} \leq 20 \% \mathrm{o} . \\
0 & z a \varepsilon_{s} \geq 20 \% \mathrm{o}
\end{array}\right.
$$

where:

$$
\varepsilon_{s}=\varepsilon_{t} \cdot \frac{d-x}{h-x} .
$$

The total tensile force is composed of three members: the contribution of UHPFRC $\left(F_{t}\right)$, classical reinforcement and prestressing cables. The contribution of UHPFRC is calculated according to the mentioned model of behaviour (10).

where: $d$ is the distance of the centre of gravity of the reinforcement from the pressed outer face of the crosssection.

\section{Experiment}

\subsection{Component materials and designing a UHPC mixture}

Designing a mixture of ultra high performance concrete is based on the principle that material with the minimum defects (such micro cracks and pores within the cement matrix) can create the highest percentage of potential hardness thanks to the high quality of its component materials. A composition of UHPC contains at least two times more component materials than conventional concrete. This is because it has more than five powdered components, which are added in their dry state and are homogenized by mixing before the water is added (cement, silica fume, quartz sand or volcanic aggregate separated into fractions of up to $8 \mathrm{~mm}$, quartz powder).

Portland cement CEM I 42.5 R was used in the experiment. The selection of Portland cement was made on the basis of its compatibility with chemical and mineral additives found in the author's experimental research into the physical and mechanical properties of samples prepared from three different cements and superplasticizers from different manufacturers. (Janković et al. 2010). Silica fume (SF) SikaFume HR manufactured by Sika was used as a mineral additive with the fine particle size of $0.1 \mathrm{~mm}$ of latent reactive silicon dioxide. The physicomechanical properties of the cement are shown in Table 1 .

When preparing the UHPC mixture, quartz sand was used as a commercial product from the firm Kaolin Valjevo, with the grain size of $0-0.5 \mathrm{~mm}$, as was Srbokvarc Rgotina quartz powder with a grain size of $d_{50 \%}=45 \mathrm{~mm}$. Examination of the grain size distribution of the quartz sand showed that about $70 \%$ of the grains are between 0.2 and $0.4 \mathrm{~mm}$.
Table 1. Physical, chemical and mechanical properties of cement and silica fume

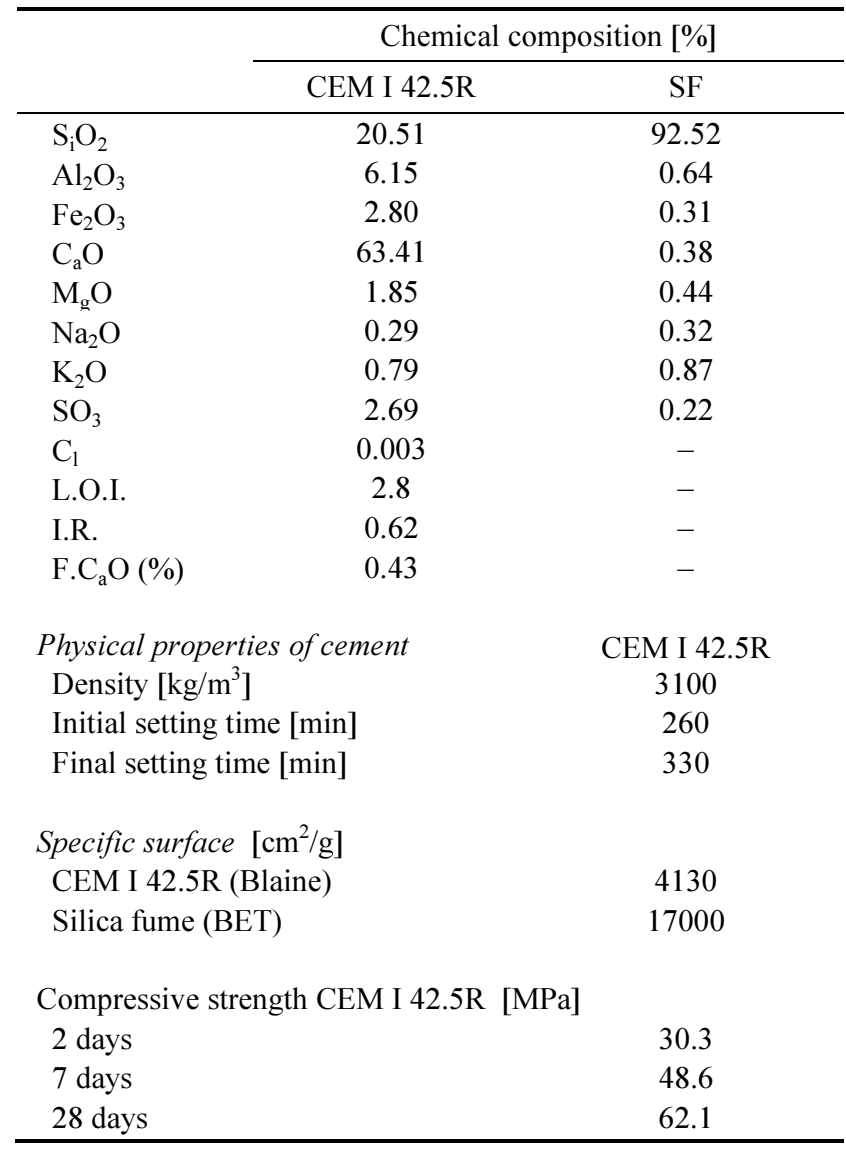

For preparing the ultra high performance concrete mixture, the superplasticizer Sika Viscocrete 20HE was used, which made high water reduction and getting very high early strength. It is the third generation of superplasticizers intended for producing concrete of plastic consistency with a special formula for improving the dispersion of powdered materials in the concrete.

Straight steel fibres were used (length/diameter $=$ $9 / 0.20 \mathrm{~mm}$ ) with a tensile resistance of $\approx 2500 \mathrm{~N} / \mathrm{mm}^{2}$. The steel fibres were brass coated to increase their durability and resistance to corrosion in the concrete.

The proportions of the component materials were adopted on the basis of research into the properties of the component materials, mixture designs shown in different 
reading sources (Yazic1 et al. 2009; Cwizen et al. 2008; Lubbers 2003) and the author's own experimental research (Janković et al. 2010). The amount of cement varied between $900 \mathrm{~kg} / \mathrm{m}^{3}$ and $1050 \mathrm{~kg} / \mathrm{m}^{3}$. Mixtures with self compacting consistency were adopted (Table 2 ).

Table 2. Mixture proportions of UHPC

\begin{tabular}{lcc}
\hline \multicolumn{1}{c}{ Material } & US2Sf2 & US2Sf4 \\
\hline Cement $\left(\mathrm{kg} / \mathrm{m}^{3}\right)$ & 950 & 950 \\
Silica fume $\left(\mathrm{kg} / \mathrm{m}^{3}\right)$ & 270 & 270 \\
Quartz powder & 350 & 350 \\
0-0.5 mm Quartz sand & 520 & 515 \\
Water & 235 & 235 \\
Superpl. Viscocrete 20HE & 55 & 53 \\
Steel fibres & 155 & 310 \\
Water from the superpl. & 31.9 & 30.7 \\
Water to binder ratio $(\mathrm{w} / \mathrm{b})$ & 0.219 & 0.218 \\
Flow slump $(\mathrm{mm})$ & 274 & 277 \\
\hline
\end{tabular}

During the mixing process, it is essential that the particles of powdered material fill the free space between the aggregate grains or the larger particles of other component materials. Due to the high content of powdered material mixing needs to take a little longer in order for the composition of the mix to become homogenized. First, all of the component materials in a solid state are mixed together, and then mixing is continued for another couple of minutes before the water is added, which reduces the remaining empty space within the mixture. After this, by adding water and a superplasticizer (if in a liquid state) the specified space is filled, and the film created around the particles improves their mobility whilst also improving their packing. Optimal choice of mixing length before and after adding water reduces the value of the water/binder ratio.

For making prisms of $4 \times 4 \times 16 \mathrm{~cm}$ a standard cement mixer for Toni Technik cement was used which fulfils the requirements of safety standard SRPS EN 196, while the mixture for the prisms of $10 \times 10 \times 40 \mathrm{~cm}$ was made in a Czech "Zyklos" mixer, with a capacity of 601 and a mixing speed of $60 \mathrm{o} / \mathrm{min}$. After being released from the moulds, the specimens were placed in water at $20^{\circ} \mathrm{C}$ for 2,7 and 28 days. UHPC for the beam samples of $12 \times 30 \times 200 \mathrm{~cm}$ was made in a Schlosser mixer with a capacity of $120 \mathrm{l}$ and a mixing speed of $70 \mathrm{o} / \mathrm{min}$. After being taken out of the mould the samples were maintained under ambient conditions (at room temperature of $20{ }^{\circ} \mathrm{C}$ and relative humidity between $45 \%$ and $65 \%$ ).

\subsection{Results of testing the mechanical properties of UHPC}

The results of the compressive strength tests are shown graphically in Figures 3 and 4 . The testing was completed according to SRPS EN 196-1 standards on prisms of $4 \times 4 \times 16 \mathrm{~cm}$ after testing the flexural strength (modified method). In Figure 4 the results are given for the compressive strength of prisms of $10 \times 10 \times 40$ (modified method). The results shown represent the average of three test samples.
The results shown illustrate a growth in the compressive strength with an increase in the volume proportion of steel fibres. The growth in the compressive strength of samples of 28 days with $4 \%$ of steel fibres when compared to samples produced with $2 \%$ of steel fibres was $6.1 \%$. That relationship for samples with the dimensions $10 \times 10 \times 40 \mathrm{~cm}$ was $16.1 \%$.

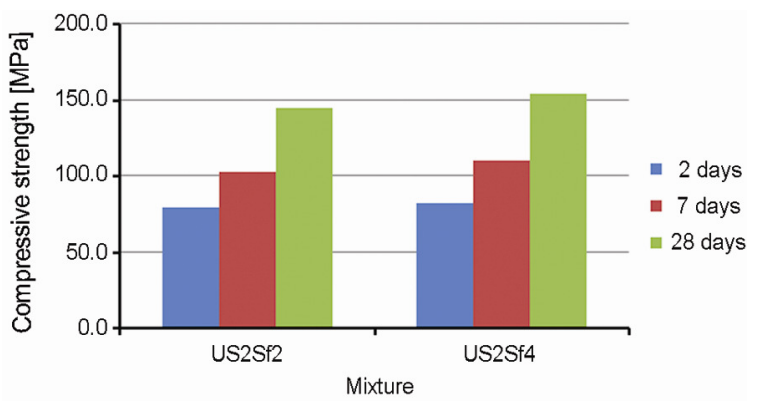

Fig. 3. Compressive strength test results on samples of $4 \times 4 \times 16 \mathrm{~cm}$

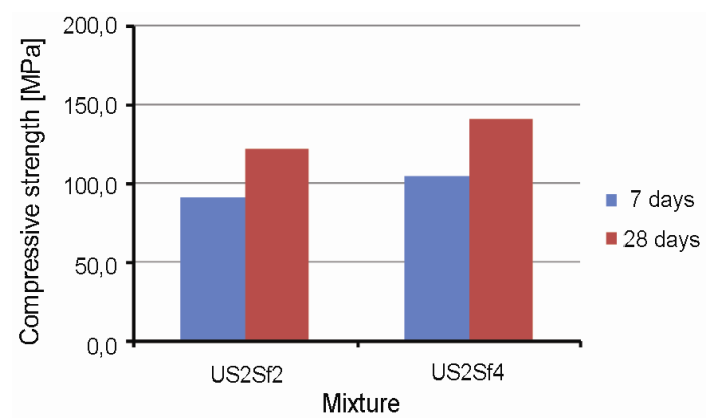

Fig. 4. Compressive strength test results on samples of $10 \times 10 \times 40 \mathrm{~cm}$

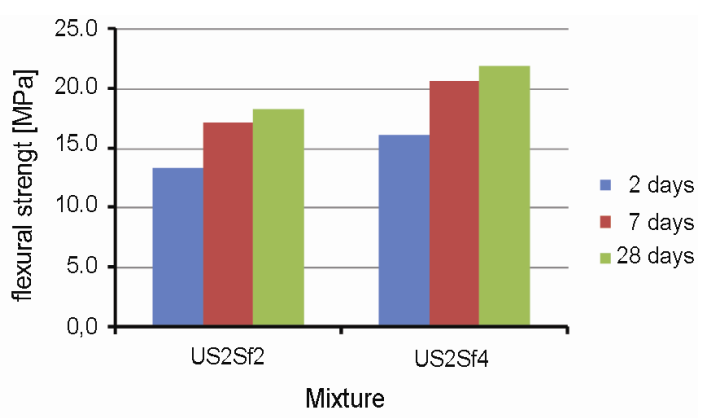

Fig. 5. Flexural strength test results on samples of $4 \times 4 \times 16 \mathrm{~cm}$

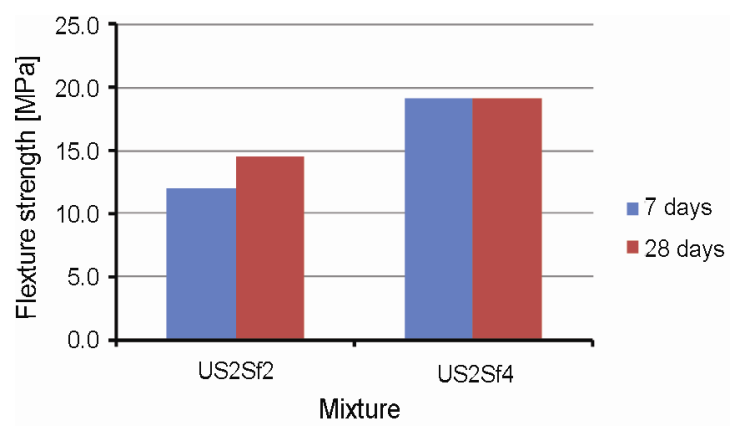

Fig. 6. Flexural strength test results on samples of $10 \times 10 \times 40 \mathrm{~cm}$ 
As expected, the test results for flexural strength of the samples directly depend on the content of steel fibres. The growth in flexural strength of the samples of $4 \times 4 \times 16 \mathrm{~cm}$ with $4 \%$ steel fibres in relation to samples with $2 \%$ of steel fibres at 28 days was $20.3 \%$. For prisms of $10 \times 10 \times 40 \mathrm{~cm}$ that relationship was $31.7 \%$.

After 28 days the prisms of $10 \times 10 \times 40 \mathrm{~cm}$ prepared with the mixtures specified in Table 2 were measured to find the load-deflection relationship. The load is applied in the middle range on the span. Supports were placed at $5 \mathrm{~cm}$ from the furthest edge ( $30 \mathrm{~cm}$ range), and the deflection was measured with an accuracy of $1 / 1000 \mathrm{~mm}$ at an interval of $1 \mathrm{KN}$. From the test results shown in Figure 7 it is evident that with an increase in the volume share of steel fibres there is an increase in both the hardness value when the cracks appear and the final flexural strength. An increase in the strength can also be seen with an increase in the steel fibre content.

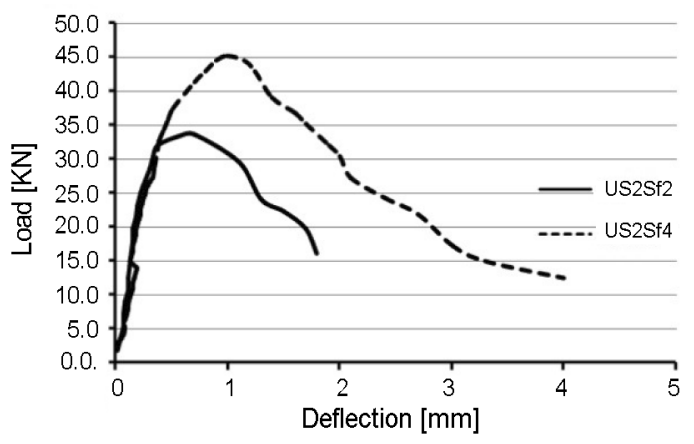

Fig. 7. The load - midspan deflection relationship in bending test

\subsection{The behaviour of UHPFRC beams subject to bending}

Concrete is a multiphase material with a number of parameters, which influence the way a construction responds to loading. There are a variety of models which describe the properties of concrete, while the number of parameters, which influence the given properties, are chosen on the basis of their proportions or influence on the beam at a macro or micro level.

In the laboratory for concrete and construction of the IMS Institute (Fig. 8) four beams of $2 \mathrm{~m}$ in length were experimentally tested (cross-section $0.12 \times 0.3 \mathrm{~m}$ ).

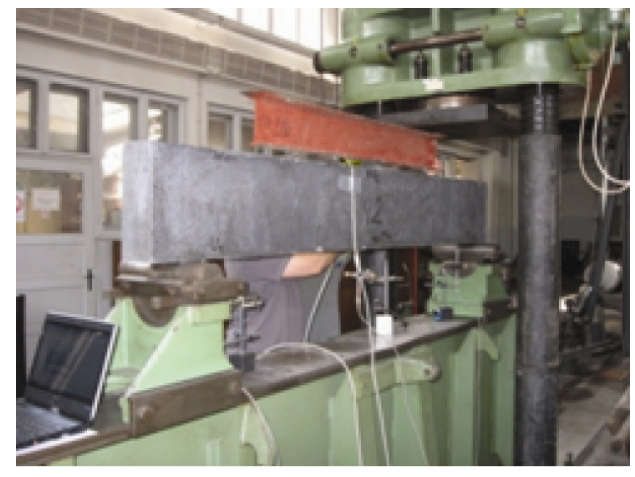

Fig. 8. Testing a beam at the laboratory of the IMS Institute
In this part of the experiment, attention is focused on modeling the behaviour of UHPFRC when subject to bending. Based on the equilibrium force in the crosssection, an analytical model of the expressed behaviour is shown in (9), (10) and (11). The given model observes the behaviour of the material under pressure, that is under stress, highlighting the differences between UHPFRC compared with conventional concretes.
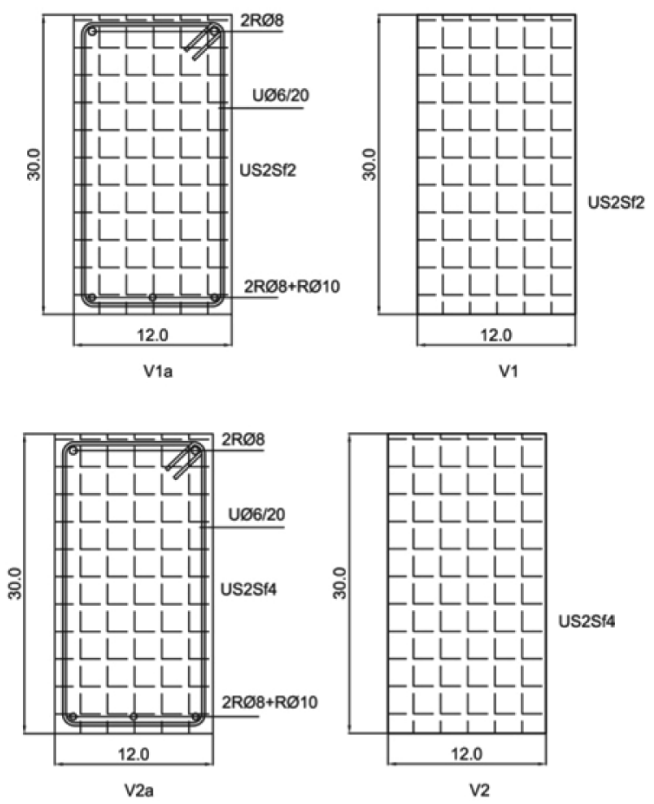

Fig. 9. Cross-section of tested beams

The difference in the behaviour of concrete without fibres given in EC2 is particularly highlighted. The presence of prestressing cables is not considered in the composite behaviour model itself, but rather during optimization it is taken into account when determining the loading capacity.

The tensile stress was determined on the basis of testing the bending of prisms loaded without cuts in the middle of the range according to Annex 2 in the French recommendations for UHPC. For the mixtures US2Sf2 and US2Sf4 diagrams of load-deflection were produced. In Figure 9, beam cross-sections are shown whose abbreviated symbols are indicated in Figures 10-12 where load-deflection and bending moment-curvature relationship are shown.

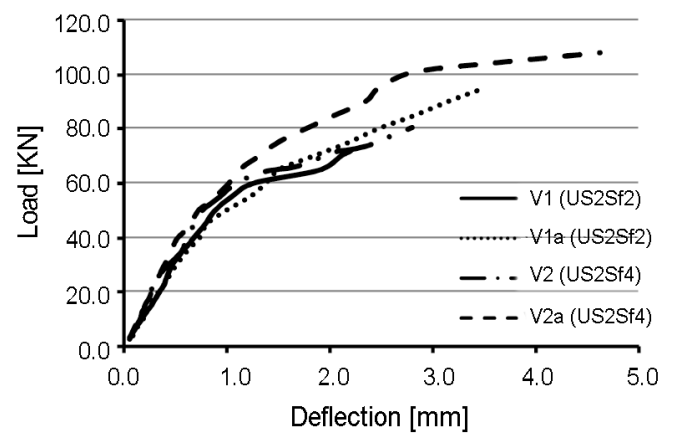

Fig. 10. Load-deflection relationship for tested beams 
UHPFRC has significantly improved ductility, and this becomes even more pronounced with an increase in the amount of fibres. However, the tensile strength in the strained zone is reached very quickly if conventional or prestressed reinforcement is not applied. In Figures 1112 , it can be seen that beams without conventional reinforcement have significantly lower loading capacity, since the stress in the pressed zone cannot be sufficiently used.

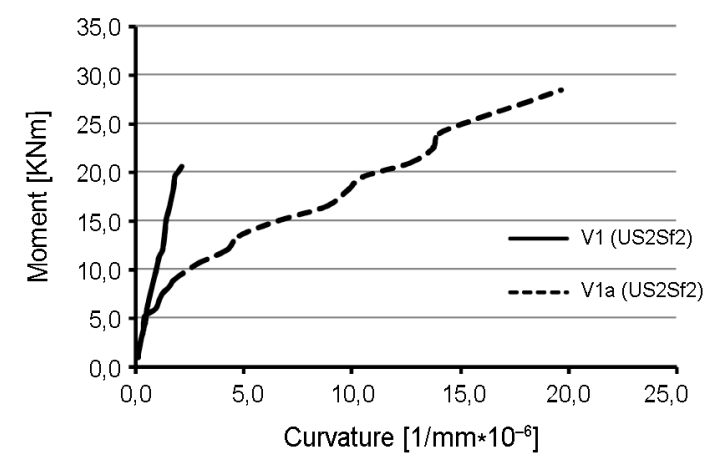

Fig. 11. The dependence of bending moment and curvature curve (mixture with a $2 \%$ share of steel fibres)

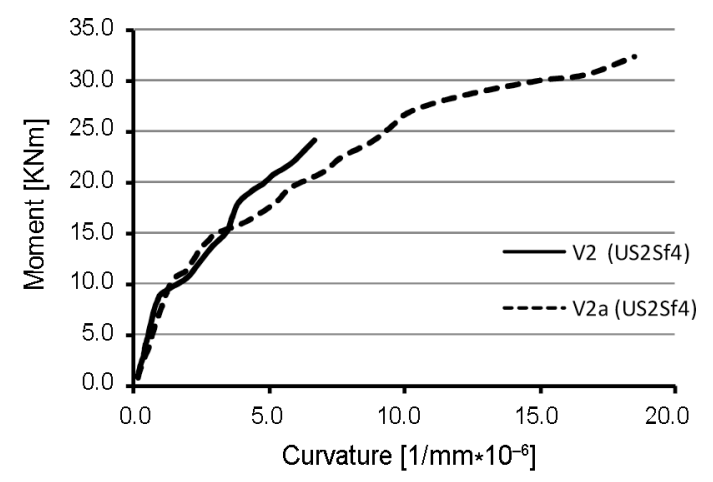

Fig. 12. The dependence of the bending moment and curvature curve (mixture with a $4 \%$ share of steel fibres)

\section{Optimization of UHPFRC beams using genetic algorithms}

In an approach with a genetic algorithm for solving engineering optimization problems, the optimal solution is found with a given accuracy, depending on the selected chain lengths (chromosomes). In this sense, a genetic algorithm usually provides an effective approach to solving big problems, because it requires only simple function development. A solution close to the optimum can be obtained after a limited number of iterations.

The problem of the optimal dimensioning of reinforced concrete beams has been considered for many years (Camp et al. 2003; Govindaraj, Ramasamy 2005; Senouci, Al-Ansari 2009; Martí, Vidosa 2010; Mohači et al. 2010). In this paper, an optimization procedure is given that aims for the adopted cross-section to satisfy the conditions of the ultimate limit state according to the criterion of minimum price of the component materials.
It is necessary to determine the target function:

$$
z=\min f(x), x=\left[x_{1}, x_{2}, \ldots, x_{n}\right],
$$

on the basis of the balance of force in the cross-section, and with the limits of the conditions, which relate to the geometric characteristics of the beams and the mechanical properties of the composite compared to the content of silica fume, steel fibres and the care regime used.

The optimal solution can come from a large number of solutions based on a selected criterion, which could be minimal weight or minimal cost. The paper will show the general formulation of cost optimization for a rectangular beam cross-section including the concrete cost, which includes the cost of steel fibres, classical reinforcement and prestressing cables. The resulting optimization problem will be solved using genetic algorithms. The problem under consideration in this paper refers to the optimization of the expenditure of materials according to the criterion of minimum price.

The price resulting from optimization in this paper represents the cost of materials for making metre-long beams. The expenditure of manpower and resources during reinforcement and working on prestressing is closely related to the equipment offered by firms and databases concerned with the analysis of resource expenditure in the preceding period, and it is necessary for the item to be independent of analysis (Ćirović, Cekić 2002).

The target function can be defined as the total cost function represented in the form of:

$$
(x)=c_{1} \cdot A_{b p}+c_{2} \cdot A_{a}+c_{3} \cdot A_{p n},
$$

where: $c_{1}$ is the unit cost of a volume of UHPC; $A_{b p}-$ the surface area of the beam cross-section; $c_{2}$ - the price of a kilogram of classical reinforcement B-500-B $(0.6 \mathrm{Eur} / \mathrm{kg}) ; A_{a}$ - the surface area of the classical reinforcement; $c_{3}$ - the price of a kilogram of prestressing cables Y-1860-S7 (1.5 Eur $/ \mathrm{kg}) ; A_{p n}$ the surface area of the prestressing cables.

With restrictions:

- for the ultimate limit state:

$$
\begin{gathered}
\sum N_{i}-N_{u}=0 \\
\sum M_{i}-M_{u}=0 ;
\end{gathered}
$$

- for the serviceability limit state:

$$
\begin{gathered}
\delta_{i} \leq \delta_{\text {lim }}=\frac{l}{250} \\
M_{S d} \leq M_{R d} \\
\left|V_{S d}\right| \leq V_{R d} .
\end{gathered}
$$

Table 3 shows the individual prices and the composite price for the mixtures given in Table 2 . The prices given are average price in concrete industry without discount except for superplasticizer and are inclusive of 
transport to the concrete factory in the Belgrade area. The superplasticizers are mostly used in making conventional concrete and unit price for Viscocrete 20HE is given with most commonly discount. It should be kept in mind that the price of steel fibres changes fairly regularly, and as a result the price of the composite varies depending on the price of the steel fibres.

Table 3. Unit prices of component materials and composites for the given mixtures

\begin{tabular}{lccc}
\hline \multicolumn{1}{c}{ Material } & Unit price & US2Sf2 & US2Sf4 \\
\hline Cement (eur/t) & 93 & 88.4 & 88.4 \\
Silica fume (eur/t) & 850 & 229.5 & 229.5 \\
Quartz powder (eur/t) & 135 & 47.3 & 47.3 \\
0-0.5 mm Quartz sand & 64 & 33.3 & 33.0 \\
(eur/t) & 0.35 & 0.1 & 0.1 \\
Water (eur $\left./ \mathrm{m}^{3}\right)$ & 1.9 & 104.5 & 100.7 \\
Superpl. Viscocrete 20HE & 3.3 & 511.5 & 1023.0 \\
(eur $/ \mathrm{kg}$ ) & & 1014.5 & 1521.8 \\
Steel fibers (eur $/ \mathrm{kg})$ & & & \\
\hline SUM [eur $/ \mathrm{m}^{3}$ ] & &
\end{tabular}

Based on the use of the Matlab application for the optimization of the loading capacity of UHPFRC beams, the loading capacity of a cross-section was determined. For an adopted cross-section width of $b=25 \mathrm{~cm}$, the optimization parameters according to the criterion of minimum cost were:

- cross-section height;

- height of the pressed zone;

- dilation of the pressed zone;

- classical reinforcement surface area;

- prestressed reinforcement surface area.

One of the primary problems in applying GA relates to the choice of GA parameter values (population size, maximum number of generations, values related to mutation and the crossing rate). Based on the experience in this example, it is an iterative process that requires a great deal of time. It is necessary to set the GA parameters in line with the required accuracy of the solution, namely the toleration, which is connected to the acceptability interval of the results of the optimization. A population size of 500 individuals and 50 generations were chosen. For the parameter values of the mutation, 0.1 was adopted, and a crossing rate of 0.1 to 0.9 with an increment of 0.1 . The results of the optimization are shown in Figure 13 and Figure 14 (Vl - steel fibre, KA - classical steel reinforcement, $\mathrm{PN}$ - prestressed reinforcement).

On the basis of the dependence of the price and ultimate limit moment for the given optimization model, the contribution of prestressing on the loading capacity and the economic acceptability of UHPFRC beams is very pronounced. Based on the achieved mechanical properties of the composites shown in Section 2, beam samples made with $4 \%$ of steel fibres for the loading capacity limit of $110 \mathrm{KNm}$ had a price of over $40 \%$ greater than beams with $2 \%$ of steel fibres. Prestressed beams for the same price (Eur $/ \mathrm{m})$ had a 3.5 times greater loading capacity than beams reinforced with only steel fibres.

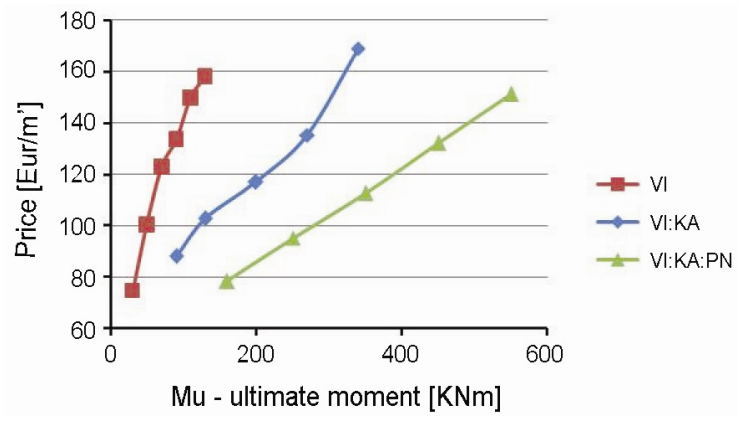

Fig. 13. The relationship between loading capacity limit and unit beam price, mixture US2Sf2

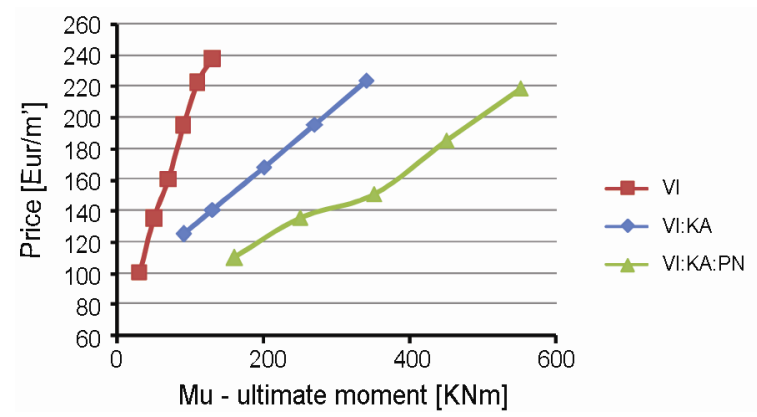

Fig. 14. The relationship between the loading capacity limit and the unit beam price, mixture US2Sf4

\section{Conclusion}

Predicting the behaviour of UHPFRC beams subject to bending is somewhat a complex process. Above all, it is necessary to determine the mechanical properties of the composite itself, and then follow recommendations to design a cross-section. Since UHPFRC is a notably more expensive material than conventional concrete, besides the attention that should be given to the loading capacity and durability of a construction it is essential to pay attention to its economic viability.

The use of genetic algorithms makes it possible to search a large area of potential solutions with a large number of parameters in a relatively short time period, and justification for the use of UHPFRC is directly dependent on the success of the optimization process. The important parameters for beams are load, beam dimensions and the properties to be met by the composite. Savings can be achieved when the optimal relationship between the component materials and the percentage of reinforcement is far more pronounced when compared with conventional materials, which most certainly justifies the time spent in optimization.

Modelling the behaviour of steel fibre reinforced concrete, and in particular steel fibre reinforced concrete of exceptionally high mechanical properties such as UHPFRC, must be based on previous experimental studies. This paper presents the dependence of the mechanical properties of UHPC with $4 \%$ and $2 \%$ of steel fibres. It can be concluded that the increase in compressive strength for samples of $10 \times 10 \times 40 \mathrm{~cm}$ for the given quantities of fibres was 2.6 times higher than the growth in samples of $4 \times 4 \times 16 \mathrm{~cm}$. The above marked difference in 
the increase in hardness is the consequence of a fall by $16 \%$ in the compressive strength in samples of $10 \times 10 \times 40 \mathrm{~cm}$ with $2 \%$ of steel fibres. The ratio for the increase in flexural strength in samples of $10 \times 10 \times 40 \mathrm{~cm}$ and $4 \times 4 \times 16 \mathrm{~cm}$ (with $4 \%$ and $2 \%$ of steel fibres) was 0.85 .

On the basis of the relationship between the ultimate capacity and the unit cost of beams (shown in Figs 13 and 14), it can be seen that an increased proportion of steel fibres increases the mechanical properties of UHPFRC, but still not enough to be able to accept more significant load values without the use of conventional reinforcement. A much higher loading capacity was demonstrated when prestressed reinforcement was applied. For the indicated unit price, the loading capacity of beams with steel fibres was more than 3.5 times lower than reinforced beams with the same amount of steel fibres. When using classical reinforcement rather than prestressed beams, for the same unit price, the loading capacity was reduced by more than 1.7 times.

\section{Acknowledgements}

This work was part of the TR 36017 project, funded under the Ministry of Education and Science of the Republic of Serbia.

\section{References}

Arslan, G.; Cihanli, E. 2010. Curvature ductility prediction of reinforced high-strength concrete beam sections, Journal of Civil Engineering and Management 16(4): 462-470. http://dx.doi.org/10.3846/jcem.2010.52

Camp, C. V.; Pezeshk, S.; Hansson, H. 2003. Flexural design reinforced concrete frames using a genetic algorithm, ASCE Journal of Structural Engineering 129(1):105-115. http://dx.doi.org/10.1061/(ASCE)07339445(2003)129:1(105)

Campione, G. 2008. Simplified flexural response of steel fiberreinforced concrete beams, Journal of Materials in Civil Engineering 20(4): 283-293.

http://dx.doi.org/10.1061/(ASCE)08991561(2008)20:4(283)

Cheung, A.; Leung, C. 2011. Shrinkage reduction of high strength fiber reinforced cementitious composites (HSFRCC) with various water-to-binder ratios, Cement \& Concrete Composites 33(6): 661-667. http://dx.doi.org/10.1016/j.cemconcomp.2011.03.009

Ćirović, G.; Cekić, Z. 2002. Communications and forum: casebased reasoning model applied as a decision support for construction projects, Kybernetes - The International Journal of Systems and Cybernetics 31(6): 896-909. http://dx.doi.org/10.1108/03684920210432844

Cwirzen, A.; Penttala, V.; Vornanen, C. 2008. Reactive powder based concretes: mechanical properties, durability and hybrid use with OPC, Cement and Concrete Research 38(10): 1217-1226. http://dx.doi.org/10.1016/j.cemconres.2008.03.013

Ding, Y.; Liu, H.; Pacheco-Torgal, F.; Jalali, S. 2011. Experimental investigation on the mechanical behaviour of the fiber reinforced high-performance concrete tunnel segment, Composite Structures 93(4): 1284-1289. http://dx.doi.org/10.1016/j.compstruct.2010.10.006
Dvorkin, L.; Dvorkin, O.; Zhitkovsky, V.; Ribakov, V. 2011. A method for optimal design of steel fiber reinforced concrete composition, Materials and Design 32(6): 32543262. http://dx.doi.org/10.1016/j.matdes.2011.02.036

Govindaraj, V.; Ramasamy, J. V. 2005. Optimum detailed design of reinforced concrete continuous beams using genetic algorithms, Computers and Structures 84(1-2): 34-48. http://dx.doi.org/10.1016/j.compstruc.2005.09.001

Habel, K.; Viviani, M.; Denaric, E.; Brühwiler, E. 2006. Development of the mechanical properties of an Ultra-High Performance Fiber Reinforced Concrete (UHPFRC), Cement and Concrete Research 36(7): 1362-1370. http://dx.doi.org/10.1016/j.cemconres.2006.03.009

Ichinomiya, T.; Hishiki, Y.; Ohno, T.; Morita, Y.; Takada, K. 2005. Experimental study on mechanical properties of ultra-high-strength concrete with low autogenous-shrinkage, American Concrete Institution, Special Publication, No. SP-228, 1341-1352.

Jankovic, K.; Bojovic, D.; Nikolic, D.; Loncar, Lj. 2010. Some properties of ultra high strength concrete, Gradevinski Materijali i Konstrukcije 53(1):43-51.

JSCE Recommendation for Design and Construction of Ultra High-Strength Fiber-Reinforced Concrete Structures (UFC). 2004. Japanese Society of Civil Engineers.

Kang, S. T.; Lee, Y.; Park, Y. D.; Kim, Y. K. 2010. Tensile fracture properties of an Ultra High Performance Fiber Reinforced Concrete (UHPFRC) with steel fiber, Composite Structures 92(1): 61-71. http://dx.doi.org/10.1016/j.compstruct.2009.06.012

Lapko, A.; Sadowska-Buraczewska, B.; Tomaszewicz, A. 2005. Experimental and numerical analysis of flexural composite beams with partial use of high strength/high performance concrete, Journal of Civil Engineering and Management 11(2): 115-120.

http://dx.doi.org/10.1080/13923730.2005.9636340

Lubbers, A. R. 2003. Bond performance between ultra-high performance concrete and prestressing strands: MSc Thesis, Ohio University, USA.

Malešev, M.; Radonjanin, V.; Ršumović, M. 2002. Uticaj novih vrsta cementa na svojstva betona, Gradevinski Materijali $i$ Konstrukcije 45(2-3): 64-68.

Martí, J. V.; Vidosa, F. G. 2010. Design of prestressed concrete precast pedestrian bridges by heuristic optimization, $A d$ vances in Engineering Software 41(7-8): 916-922. http://dx.doi.org/10.1016/j.advengsoft.2010.05.003

Mohači, D.; Mučenski, V.; Trivunić M.; Peško, I. 2010. Choosing an optimal type of facade wall using "Designbuilder" software package, Građevinski Materijali i Konstrukcije 53(1): 3-13.

Ranković, S.; Folić, R.; Mijalković, M. 2010. Effects of RC beams reinfocement using near surface mounted reinforced FRP composites, Facta Universitatis - Series: Architecture and Civil Engineering 8(2): 177-185. http://dx.doi.org/10.2298/FUACE1002177R

Redaelli, D.; Muttoni, A. 2007. Tensile behaviour of reinforced ultra-high performance fiber reinforced concrete elements, in Fib Symposium, 2007, Dubrovnik, Croatia, 267274 .

Rougeau, P.; Borys, B. 2004. Ultra high performance concrete with ultrafine particles other than silica fume, in International Symposium on Ultra High Performance Concrete, 2004, Kassel, Germany, 213-225. 
Senouci, A. B.; Al-Ansari, M. S. 2009. Cost optimization of composite beams using genetic algorithms, Advances in Engineering Software 40(11): 1112-1118. http://dx.doi.org/10.1016/j.advengsoft.2009.06.001

Sobolev, K.; Amirjanov, A. 2010. Application of genetic algorithm for modeling of dense packing of concrete aggregates, Construction and Building Materials 24(8): 14491455. http://dx.doi.org/10.1016/j.conbuildmat.2010.01.010

Ultra-High Performance Fibre-Reinforced Concrete, Interim Recommendations. 2002. AFGC/SETRA working group.

Yang, I. H.; Joh, C.; Kim, B. S. 2010. Structural behavior of ultra high performance concrete beams subjected to bending, Engineering Structures 32(11): 3478-3487. http://dx.doi.org/10.1016/j.engstruct.2010.07.017

Yang, S. L.; Millard, S. G.; Soutsosb, M. N.; Barnett , S. J.; Le, T. T. 2009. Influence of aggregate and curing regime on the mechanical properties of ultra-high performance fibre reinforced concrete (UHPFRC), Construction and Building Materials 23(6): 2291-2298.

http://dx.doi.org/10.1016/j.conbuildmat.2008.11.012
Yazıc1, H. 2007. The effect of curing conditions on compressive strength of ultra high strength concrete with high volume mineral admixtures, Building and Environment 42(5): 2083-2089. http://dx.doi.org/10.1016/j.buildenv.2006.03.013

Yazıcı, H.; Yardımcı, M. Y.; Aydın, S.; Karabulut, A. 2009. Mechanical properties of reactive powder concrete containing mineral admixtures under different curing regimes, Construction and Building Materials 23(3): 1223-1231. http://dx.doi.org/10.1016/j.conbuildmat.2008.08.003

Zhutovsky, S.; Kovler, K. 2012. Effect of internal curing on durability-related properties of high performance concrete, Cement and Concrete Research 42(1): 20-26. http://dx.doi.org/10.1016/j.cemconres.2011.07.012

Goran ĆIROVIĆ. An Associate Professor at the Department of Civil Engineering and Geodesy, Faculty of Technical Science, Novi Sad, Serbia. He received his PhD from University of Belgrade. His main research interest is operations research in civil engineering.

Vlastimir RADONJANIN. An Associate Professor at the Department of Civil Engineering and Geodesy, Faculty of Technical Science, Novi Sad, Serbia. He leads science project "Utilization of by-products and recycled waste materials in concrete composites in the scope of sustainable construction development in Serbia: investigation and environmental assessment of possible applications" supported by the Ministry of Education and Science, Republic of Serbia. Research interests include concrete technology and durability of structural members and modern materials in civil engineering.

Milan TRIVUNIĆ. A Professor at the Department of Civil Engineering and Geodesy, Faculty of Technical Science, Novi $\mathrm{Sad}$, Serbia. His main research interest is modelling and optimization processes in prefabricated reinforced concrete construction.

Dragan NIKOLIĆ. MSc, a Research Assistant at the Institute for Testing Materials, Belgrade, Serbia. His main research interest is the behaviour of cement based composites with very high compressive strength. 